\title{
Retinal involvement in sepsis: from the eye of the patient to the eye of the beholder
}

\author{
E. Christiaan Boerma \\ See related research by Erikson et al., https://ccforum.biomedcentral.com/articles/10.1186/s13054-017-1676-3
}

Keywords: Sepsis, Fluorescence angiography, Retinal blood flow, Roth spot

In the history of mankind the importance of the eye has always extended beyond the organ itself. In ancient Egypt the "Eye of Horus" represented royal power and good health and reflected all six senses. In Greek mythology the symbolic value of the eye was already supported by detailed medical knowledge [1]. Not only symbolizing the giant one-eyed cyclops' limited intelligence in contrast to the vigilance of Panoptes, whose body was covered by eye's, the stories also reflected the understanding of the concepts of visual fields and acuity. In modern ophthalmology the idea of ocular involvement in systemic diseases, such as lupus and diabetes, is well established. In addition, the eye is also known as an organ that "mirrors" diseases in a distant primary organ of interest; Roth spots in endocarditis is the classic example [2].

In a recently published paper in Critical Care Erikson and co-workers extended these ideas to the context of sepsis [3]. They added direct observation of the retina to the already many-headed sepsis Hydra, which affects so many organs. Retinal fluorescein angiography was performed twice during the first 5 days in the intensive care unit in 31 patients with sepsis. In addition ocular pressure was determined. By doing so the authors demonstrated the feasibility of this technique in the local ICU setting, despite practical limitations. And the results were alarming. More than half of the patients displayed signs of retinal pathology, including fluorescein-leaking retinal micro-aneurysms, vitreous hemorrhages, and other retinal hemorrhages. These findings were bilateral in $75 \%$ of the affected cases. Ocular hypertension was present in $16 \%$ of all septic patients.

Correspondence: e.boerma@chello.n

Department of Intensive Care, Medical Centre Leeuwarden, Leeuwarden, The Netherlands

(c) The Author(s). 2017 Open Access This article is distributed under the terms of the Creative Commons Attribution 4.0 International License (http://creativecommons.org/licenses/by/4.0/), which permits unrestricted use, distribution, and reproduction in any medium, provided you give appropriate credit to the original author(s) and the source, provide a link to the Creative Commons license, and indicate if changes were made. The Creative Commons Public Domain Dedication waiver (http://creativecommons.org/publicdomain/zero/1.0/) applies to the data made available in this article, unless otherwise stated.
Such abnormalities were increasingly present in the subgroup of septic patients with a slowdown of arterial retinal blood flow, expressed as a prolonged retinal arterial filling time $>8.3 \mathrm{~s}$. In general these patients were sicker and had lower cardiac output. This led the authors to believe that retinal fluorescein angiography has potential to detect and characterize sepsis in a noninvasive way (with the exception of an intravenous fluorescent dye, that is). But as tempting as it may seem, such a search for the holy grail of an easily accessible organ that "represents" (all) other organs carries the risk of oversimplification. Recent examples of tonometry as a "canary of the body" and the sublingual microcirculation as a window for other organs remind us to be cautious $[4,5]$, especially in a disease state that is characterized by heterogeneity of blood flow within and between organs [6]. In addition, the idea to use retinal microvascular blood flow as a surrogate for intracranial perfusion is equally tempting. Previous observations have suggested that both retinal and conjunctival blood flow may, to some extent, represent cerebral blood flow changes during carotid endarterectomy [7, 8]. Others observed that retinal blood flow may reflect intracranial hypertension [9]. However, the absence of abolishment of conjunctival blood flow during angiography-proven brain death is reason to use the eye as a window for the brain with great caution [10].

Where should we go from here? Irrespective of the issue of retinal pathology as a surrogate for the effects of sepsis in other organs, what is the relevance of the findings in themselves. If more than half of sepsis patients have retinal pathology, what are the clinical consequences? Are they related to visual outcome? And do they need follow-up? The fact that, in this study, the abnormal retinal findings had resolved in a control 
angiography 3-6 months after hospital discharge in surviving patients is seemingly reassuring, but these need to be confirmed in larger high-risk patient cohorts. In addition it is known that processes other than sepsis, such as hypoxia or ischemia, may also upset the normal retina-blood barrier in the retinal capillaries, thereby allowing extravascular leakage of fluorescein. This warrants further studies to establish the incidence of retinal pathology in other high-risk ICU populations. And what about post-ICU check-ups for intraocular hypertension, usually unnoticed by the patient until irreversible visual damage has occurred. With an increasing ICU survival rate even for very complicated disease states such as sepsis, the ICU community is becoming more and more aware of post-ICU sequelae, also referred to as postintensive care syndrome (PICS) [11]. In addition to ICUacquired weakness and cognitive impairment, even a small deterioration in visual abilities may be very relevant for daily life activities, especially in the frail elderly with a pre-existing decline in function of potentially all six senses prior to and after ICU admission [12].

We thank doctor Erikson and his colleagues for their effort to cross the (imaginary) border between the ICU and the ophthalmology department. Their innovative research has made the ICU community aware of the fact that sepsis, and potentially other critically ill disease states, may affect the eyes of ICU patients. Undoubtedly this will change the eye of the beholder as well.

\section{Acknowledgements \\ None.}

\section{Funding}

None.

Availability of data and materials

Not applicable.

\section{Authors' contributions}

ECB wrote the commentary and read and approved the final version.

Authors' information

Not applicable.

\section{Competing interests}

The authors declare that they have no competing interests.

\section{Consent for publication}

Not applicable.

Ethics approval and consent to participate

Not applicable.

\section{Publisher's Note}

Springer Nature remains neutral with regard to jurisdictional claims in published maps and institutional affiliations.

Published online: 17 June 2017

\section{References}

1. Trompoukis C, Kourkoutas D. Greek mythology: the eye, ophthalmology, eye disease, and blindness. Can J Ophthalmol. 2007;42(3):455-9.
2. Roth M. Über Netzhautaffectionen bei Wundfiebern. I. Die embolische Panophthalmitis. Langenbecks Arch Klin Chir Ver Dtsch Z Chir. 1872;1:471-84.

3. Erikson K, Liisanantti JH, Hautala N, Koskenkari J, Kamakura R, Herzig KH, Syrjälä H, Ala-Kokko TI. Retinal arterial blood flow and retinal changes in patients with sepsis: preliminary study using fluorescein angiography. Crit Care. 2017;21(1):86.

4. Garrett SA, Pearl RG. Improved gastric tonometry for monitoring tissue perfusion: the canary sings louder. Anesth Analg. 1996;83(1):1-3.

5. Kaluski E, Milo-Cotter O, Cotter G. 'Death and life are in the power of the tongue'? Cardiology. 2009;114(1):39-41.

6. Boerma EC, van der Voort PHJ, Spronk PE, Ince C. Relationship between sublingual and intestinal microcirculatory perfusion in patients with abdominal sepsis. Crit Care Med. 2007;35(4):1055-60.

7. Schaser KD, Settmacher U, Puhl G, Zhang L, Mittlmeier T, Stover JF, Vollmar B, Menger MD, Neuhaus P, Haas NP. Noninvasive analysis of conjunctival microcirculation during carotid artery surgery reveals microvascular evidence of collateral compensation and stenosis-dependent adaptation. J Vasc Surg. 2003;37(4):789-97.

8. Enaida H, Nagata S, Takeda A, Nakao S, Ikeda Y, Ishibashi T. Changes in chorioretinal blood flow velocity and cerebral blood flow after carotid endarterectomy. Jpn J Ophthalmol. 2016;60(6):459-65.

9. Ragauskas A, Matijosaitis V, Zakelis R, Petrikonis K, Rastenyte D, Piper I, Daubaris $\mathrm{G}$. Clinical assessment of noninvasive intracranial pressure absolute value measurement method. Neurology. 2012;78(21):1684-91.

10. Tamosuitis T, Pranskunas A, Balciuniene N, Pilvinis V, Boerma EC. Conjunctival microcirculatory blood flow is altered but not abolished in brain dead patients: a prospective observational study. BMC Neurol. 2016;16:95.

11. van der Schaaf M, Dettling DS, Beelen A, Lucas C, Dongelmans DA, Nollet F. Poor functional status immediately after discharge from an intensive care unit. Disabil Rehabil. 2008;30(23):1812-8.

12. Hardin SR. Hearing loss in older critical care patients: participation in decision making. Crit Care Nurse. 2012;32(6):43-50. 